\title{
The 50th Anniversary of Establishment of the Polar Geophysical Institute
}

DOI: $10.1134 / \mathrm{S} 0016793210050014$

October 2010 marks 50 years since the establishment of the Polar Geophysical Institute (PGI) of the Kola Scientific Center of the Russian Academy of Sciences. The foundation of PGI was related to the largescale participation of researchers from the Soviet Union in the program of the International Geophysical Year (IGY, 1957-1958). One part of the IGY program was devoted to a complex study of magnetic storms and auroral phenomena. For this purpose, in anticipation of the IGY, the Murmansk Branch of the Institute of Geomagnetism, Ionosphere, and Radio Wave Propagation (IZMIRAN) of the USSR Academy of Sciences was organized in 1953 in the auroral activity zone on the Kola Peninsula. The new research center was headed by Sergey Ivanovich Isaev, a wellknown polar explorer and specialist in auroral phenomena. Later, also in anticipation of the IGY, new observatories on the Kola Peninsula at Loparskaya and Lovozero were founded. The Loparskaya Observatory was organized by the Institute of Atmospheric Physics of the USSR Academy of Sciences and intended mainly to monitor rapid variations of the Earth's magnetic field and telluric currents. The processing of a large body of data collected during the IGY and the following programs of International Geophysical Cooperation (IGC, 1959) showed evidence for the common nature of geophysical processes underlying the development of magnetic storms, substorms, and auroral phenomena and the generation of rapid variations of the Earth's electromagnetic field. Thus, the necessity of integrating separate geophysical research facilities functioning on the Kola Peninsula into a united scientific institution became evident. This resulted in establishment of PGI in October 1960 on the basis of the Murmansk Branch of IZMIRAN and the observatories at Loparskaya and Lovozero. Under the guidance of its first director, S.I. Isaev, PGI became the leading scientific center for studying magnetospheric and ionospheric processes.

In this issue, we are publishing 13 papers from researchers at PGI, which reflect the diversity of scientific problems presently studied at the institute.

\section{O.M. Raspopov,}

Editor-in-Chief of the journal Geomagnetism and Aeronomy 